\title{
Effect of Shot Peening on Surface Integrity of AerMet100 Steel
}

\author{
Qian Ang ${ }^{\mathrm{a}}$, Jin Ping ${ }^{\mathrm{b}}$, Tan Xiaoming ${ }^{\mathrm{c}}$, Wang De ${ }^{\mathrm{d}}$ \\ Qingdao Branch, Naval Aviation University, Qingdao 266041

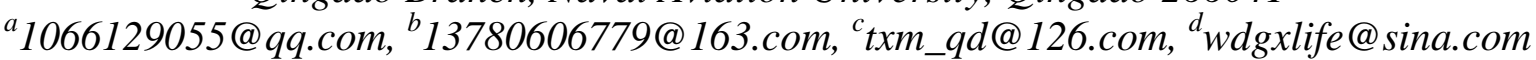

Keywords: shot peening; AerMet100 ultra high strength steel; roughness; hardness; residual compressive stress

Abstract: This paper studies the effect of shot peening on its surface properties for AerMet100 ultra-high strength steel. Scanning electron microscopy and white light interferometer were used to analyze the effects of shot peening on the surface morphology, roughness, hardness, residual stress and element content of the samples. The results show that after shot peening, a large number of craters remain on the surface of the sample, resulting in obvious plastic deformation; The surface roughness is increased, and the arithmetic mean roughness is $1.33 \mu \mathrm{m}$; The hardness is significantly increased, the hardness of the outermost layer is increased from $476 \mathrm{HV}$ before shot peening to $497 \mathrm{HV}$, and the depth of hardened layer is about $150 \mu \mathrm{m}$; The residual compressive stress value of the surface layer of the sample is increased from $-375 \mathrm{MPa}$ to $-475 \mathrm{MPa}$, the maximum residual compressive stress value is about $-518 \mathrm{MPa}$, located at a depth of $50 \mu \mathrm{m}$ from the surface, and the residual compressive stress layer formed by shot peening has a depth of about $134 \mu \mathrm{m}$; The mass fraction of $\mathrm{C}, \mathrm{Si}, \mathrm{Cr}$ and other elements in the sample after shot peening increased slightly. Shot peening improves the surface properties of ArerMet100 steel material to a certain extent, which is beneficial to improve its fatigue resistance and corrosion resistance.

\section{Introduction}

The development of the aviation industry provides a broad platform for the application of ultra-high strength steel materials. As a new type of ultra-high strength steel, AerMet100 (23Co14Ni12Cr3Mo) has good strength, toughness and fatigue properties, and is increasingly used in the manufacture of key structural components such as aircraft engines and landing gear ${ }^{[1]}$.

Under the actual service conditions, the aircraft structure is susceptible to corrosion damage and fatigue failure due to the influence of the service environment and the alternating fatigue load. Therefore, in order to improve the durability, reliability and safety of aircraft components, surface strengthening techniques are often used to increase the service life of components. The shot peening process has the characteristics of good practicability, wide application range and low price. It can significantly improve the surface properties of the material, improve its corrosion resistance and fatigue performance, and is often applied to the surface strengthening of components. Domestic and foreign scholars have also carried out many researches on the impact of shot peening on material 
properties. Xiao Zhiyu et $\mathrm{al}^{[2]}$ studied the bending fatigue performance of $\mathrm{Fe}-2 \mathrm{Cu}-2 \mathrm{Ni}-1 \mathrm{Mo}-1 \mathrm{C}$ material by shot peening. The results show that the surface of the sample before shot peening has more pores and the pore size is larger. After the shot peening, the pores of the surface layer of the sample were significantly reduced, nearly full density, and the thickness of the surface dense layer was about $70 \mu \mathrm{m}$. Sun Hanxi et $\mathrm{al}^{[3]}$ studied the effects of fatigue loading on the residual stress and microstructure of 17CrNiMo6 shot peening layer. The results show that the residual compressive stress field depth of the sample before shot peening is about $50 \mu \mathrm{m}$, and the maximum residual compressive stress is -220MPa, which is located on the surface of the sample; the residual compressive stress field depth of the sample after shot peening is $400 \mu \mathrm{m}$, and the maximum residual compressive stress is $-650 \mathrm{MPa}$, which is located at a depth of about $100 \mu \mathrm{m}$ from the surface layer. $\mathrm{Xu}$ Xingchen et $\mathrm{al}^{[4]}$ studied the effect of shot peening on the surface integrity and fatigue properties of 2060 aluminum-lithium alloy. The results show that: shot peening increases the surface roughness of the sample, and there are pits of different depths. There is obvious plastic damage rheology and cracking and delamination at the edge of the stack; the surface hardness of the sample after shot peening increases by about $9 \% \sim 12 \%$. Guo Changgang et $\mathrm{al}^{[5]}$ studied the effect of shot peening on the corrosion behavior of magnesium alloy in simulated body fluids. The results showed that the mass fraction of $\mathrm{Mg}$ in the sample decreased from $82.88 \%$ to $70.13 \%$ after shot peening, and the mass fraction of $\mathrm{Al}$ From $16.28 \%$ to $28.08 \%$, the reduction of $\mathrm{Mg}$ and the enrichment of $\mathrm{Al}$ increase the corrosion resistance of the magnesium alloy.

Shot blasting is a common method currently used for surface strengthening of metal materials. It can not only introduce favorable factors for improving fatigue performance and corrosion resistance on the surface of materials, but also cause adverse effects such as increased surface roughness and cracking of materials. In this paper, AerMet100 ultra-high strength steel was used as the research object to analyze the effect of shot peening on its surface properties, which laid a foundation for further study on the effect of shot peening on the fatigue properties and corrosion resistance of materials.

\section{Test}

\subsection{Test materials and samples}

The test material used in this paper is the new ultra-high strength steel AerMet100 (23Co14Ni12Cr3Mo), and its chemical composition is shown in Table 1. The test material was processed into a block sample having a size of $10 \times 10 \mathrm{~mm}$ and a thickness of $5 \mathrm{~mm}$ by wire cutting for shot peening.

Table 1 Chemical composition of Aermet100 (mass fraction/\%)

\begin{tabular}{cccccccc}
\hline $\mathrm{C}$ & $\mathrm{Ni}$ & $\mathrm{Co}$ & $\mathrm{Cr}$ & $\mathrm{Mo}$ & $\mathrm{Si}$ & $\mathrm{Mn}$ & $\mathrm{Fe}$ \\
\hline 0.23 & 11.73 & 13.85 & 3.13 & 1.25 & 0.10 & 0.10 & $\mathrm{Bal}$ \\
\hline
\end{tabular}

The material heat treatment system was solution treatment at $879^{\circ} \mathrm{C}$ for $1.5 \mathrm{~h}$, air cooling to $95^{\circ} \mathrm{C}$ for 3 hours, $-72^{\circ} \mathrm{C}$ deep cooling for $1.5 \mathrm{~h}$, and after rising to room temperature, it was deactivated at $483^{\circ} \mathrm{C}$ for $4.5 \mathrm{~h}$ and cooled to room temperature. Its mechanical properties are shown in Table 2.

Table 2 Mechanical properties of Aermet100

\begin{tabular}{ccccc}
\hline$\sigma_{0.2} / \mathrm{MPa}$ & $\sigma_{\mathrm{b}} / \mathrm{MPa}$ & $\delta_{\mathrm{s}} / \%$ & $\Psi / \%$ & $\mathrm{~K}_{\mathrm{IC}} /\left(\mathrm{MPa} \cdot \mathrm{m}^{1 / 2}\right)$ \\
\hline 1755 & 1970 & 13 & 65 & 120 \\
\hline
\end{tabular}

The metallographic structure of the material is shown in Fig.1. It can be seen that the 
metallographic structure of AerMet100 steel is mainly composed of lath martensite and polygonal austenite.

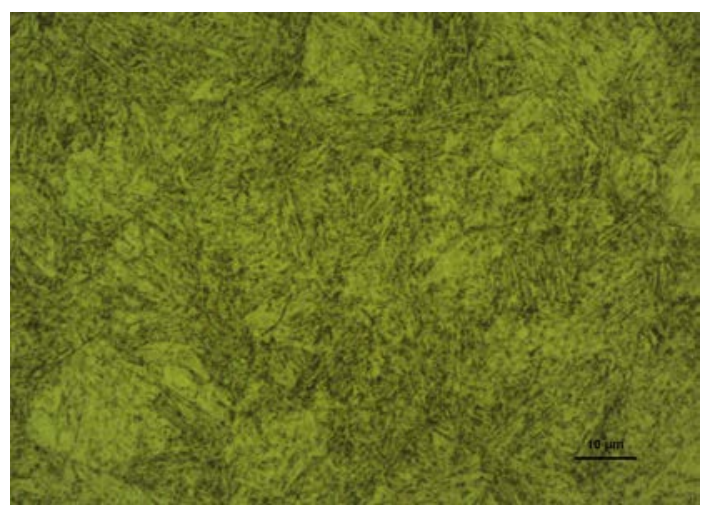

Figure.1 Metallographic organization

\subsection{Shot peening}

The test piece was subjected to shot peening according to the standard (SAE) AMS-S-13165-1997[6] using the RT3-G81-4 automatic shot blasting apparatus. The projectile is a cast steel projectile with a diameter of $0.3 \mathrm{~mm}$, a hardness of 56-60 HRC, and a shot peening rate of $200 \%$. The shot peening strength is determined to be $0.246 \mathrm{mmA}$ according to the Almen test strip saturation strength test.

\section{Test results}

\subsection{Surface topography}

The surface morphology of the sample before and after shot peening is shown in Figure 2. It can be seen that the surface of the sample before shot peening is flat and smooth, and there are obvious processing trace lines, as shown in Fig. 2(a). After the shot peening, the surface of the sample has obvious plastic deformation, leaving different craters of different sizes and different depths. The craters overlap each other, and the original processing trace disappears. See Figure 2(b).

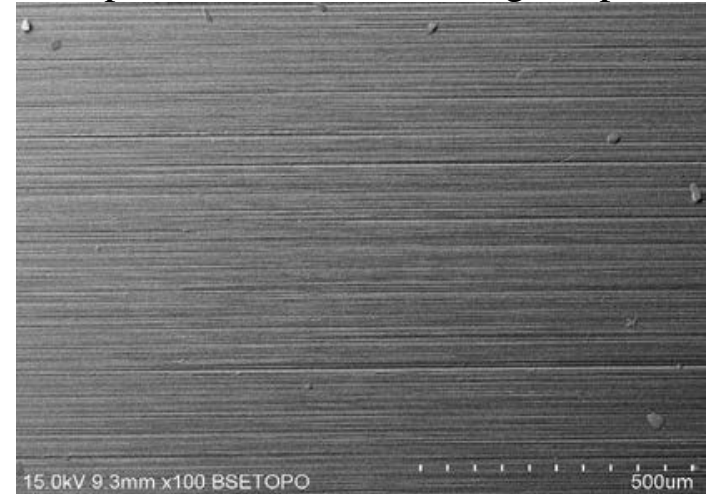

(a)

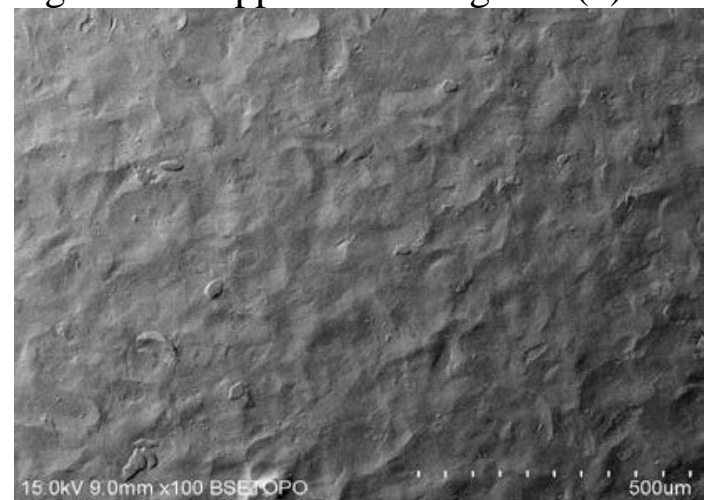

(b)

Figure.2 Surface morphology before and after shot peening

\subsection{Roughness}

The surface roughness of the sample before and after shot peening was detected by NeXView type three-dimensional white light interferometer, as shown in Fig. 3. It can be seen that the 
roughness test results reflect the surface topography of the samples before and after shot peening. It can be seen from Table 3 that the surface roughness value of the sample after shot peening is increased, and a slight increase in roughness may increase the stress concentration level on the surface of the sample ${ }^{[7]}$. Where: $\mathrm{R}_{\mathrm{a}}$ : arithmetic mean roughness; $\mathrm{R}_{\mathrm{q}}$ : root mean square roughness; $\mathrm{R}_{\mathrm{t}}$ : maximum roughness height.

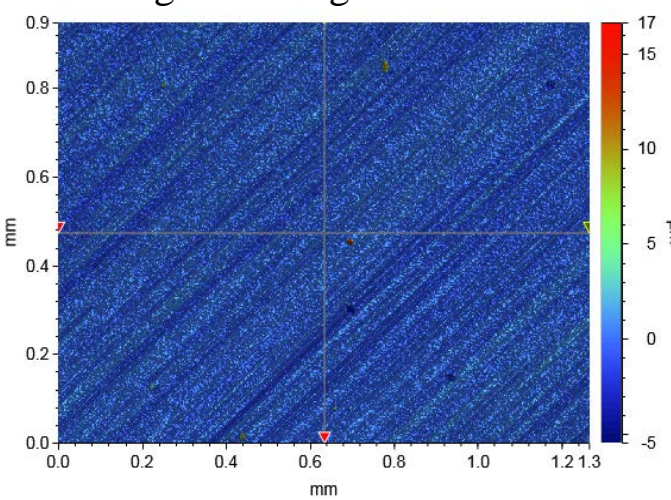

(a)

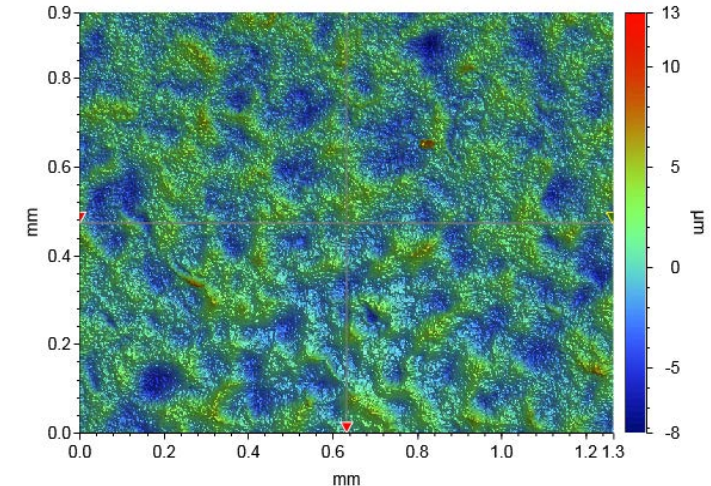

(b)

Figure.3 Roughness before and after shot peening

Table 3 Surface roughness before and after shot peening

\begin{tabular}{cccc}
\hline Specimen & $\mathrm{Ra} / \mu \mathrm{m}$ & $\mathrm{Rq} / \mu \mathrm{m}$ & $\mathrm{Rt} / \mu \mathrm{m}$ \\
\hline Unpeened & 0.47 & 0.59 & 6.62 \\
\hline Shot peened & 1.33 & 1.68 & 15.34 \\
\hline
\end{tabular}

\subsection{Hardness}

The hardness test was carried out along the depth direction of the cross section of the sample, and 3 points were tested at the same depth, and the average value was taken as the hardness value of the depth. As can be seen from Fig. 4, the hardness of the sample after shot peening is significantly increased, and the hardness of the outermost layer is increased from $476 \mathrm{HV}$ before shot peening to $497 \mathrm{HV}$, and the depth of the hardened layer is about $150 \mu \mathrm{m}$. This is because during the shot peening process, the impact of the projectile causes plastic deformation on the surface of the sample, and grain microstructure and dislocations and other microstructure changes occur in the deformed layer ${ }^{[8-10]}$, thereby improving the hardness of the sample. Changes in grain refinement and dislocations inside the sample are beneficial to improve corrosion resistance and fatigue properties $^{[11-13]}$.

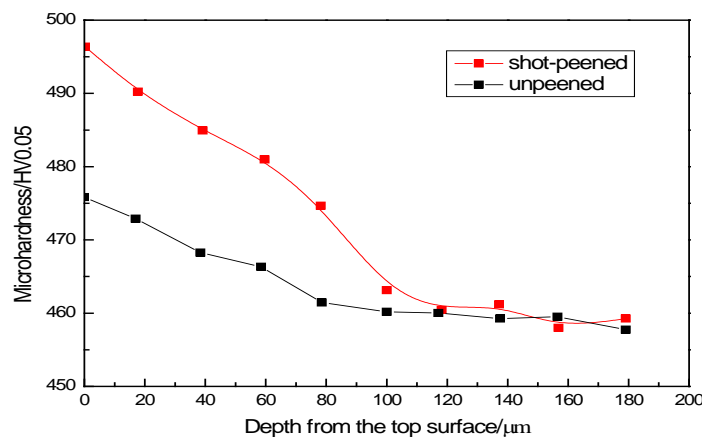

Figure.4 Hardness distribution before and after shot peening 


\subsection{Residual Stress}

The residual stress test was carried out along the depth direction of the cross section of the sample, and 4 points were tested at the same depth, and the average value was taken as the residual stress value of the depth. Figure 5 is a test result of residual stress at different depths before and after shot peening of the sample. It can be seen that the residual compressive stress value of the surface layer of the sample after shot peening is increased from -375 MPa to -475 MPa, and the maximum residual compressive stress value is about $-518 \mathrm{MPa}$. It is located at a depth of about 50 $\mu \mathrm{m}$ from the surface, and the depth of the residual compressive stress layer formed by shot peening is about $134 \mu \mathrm{m}$. The existence of residual compressive stress can offset part of the tensile stress under cyclic loading, reduce local payload, and delay the initiation and propagation of fatigue cracks ${ }^{[14,15]}$.

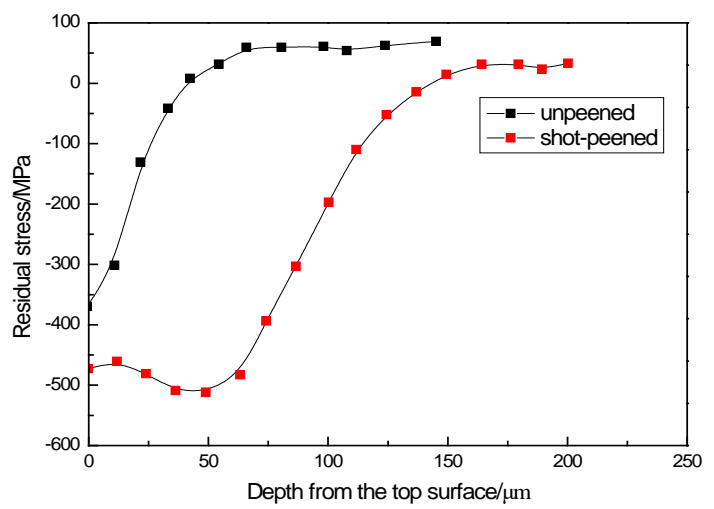

Figure.5 Distribution of residual stress before and after shot peening

\subsection{Element content}

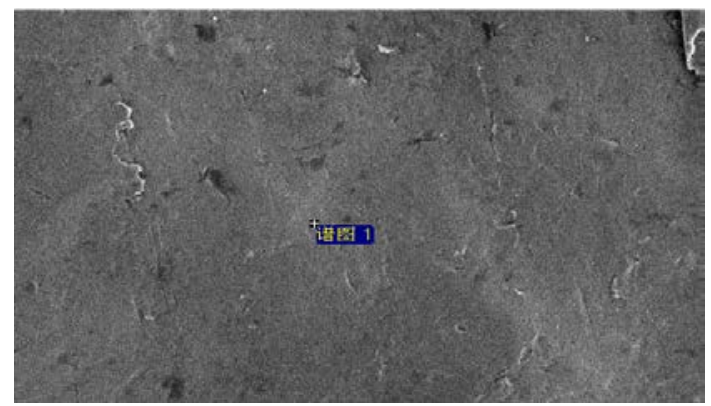

(a)

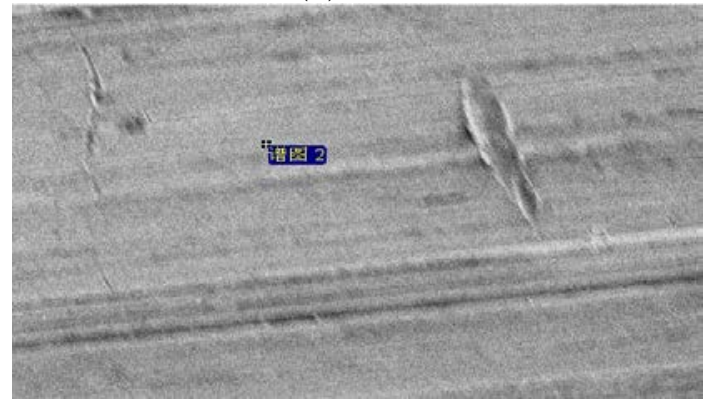

(c)

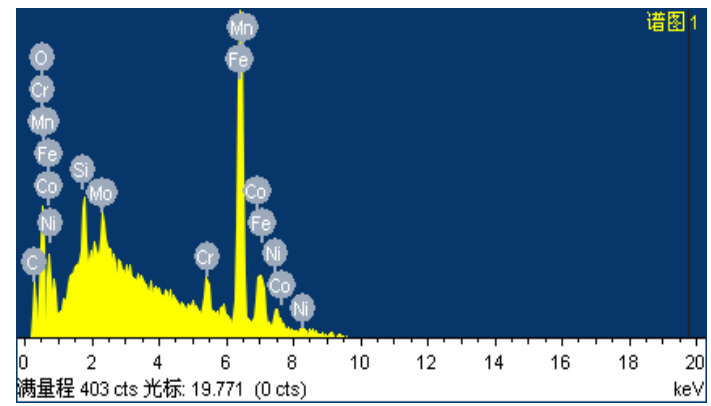

(b)

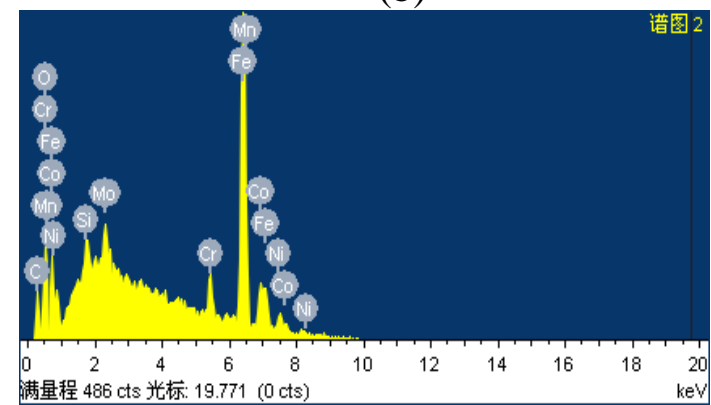

(d)

Figure.6 EDS before and after shot peening

Figs. 6(a), 6(b) and Figs. 6(c) and 6(d) are the results of EDS test after shot peening and before shot peening, respectively, and Table 4 is the content of elements in the sample before and after shot 
peening. It can be seen that the mass fraction of $\mathrm{C}, \mathrm{Si}, \mathrm{Cr}$ and other elements increased slightly after shot peening, mainly due to the phenomenon of material transfer during shot peening, At high collision rates and frequencies, contact fatigue wear occurs. During the impact process, the steel ball debris is decomposed and the alloying elements (such as $\mathrm{Cr}$, C, etc.) are transferred into the surface of the sample. Due to the concentration gradient, the alloy atoms diffuse rapidly into the depth ${ }^{[16]}$. On the other hand, the material generates a large number of defects (vacancies, dislocations, etc.) under the action of high energy collision. The formation of vacancies reduces the diffusion activation energy, and the diffusion coefficient increases, making the diffusion easy ${ }^{[17]}$.

Table 4 Element content

\begin{tabular}{ccccc}
\hline \multirow{2}{*}{ Elements } & \multicolumn{2}{c}{ Weight percentage/\% } & \multicolumn{2}{c}{ Atomic percentage/\% } \\
\cline { 2 - 5 } & Unpeened & Shot peened & Unpeened & Shot peened \\
\hline $\mathrm{C}$ & 8.36 & 8.42 & 26.76 & 26.89 \\
$\mathrm{O}$ & 5.14 & 5.46 & 12.34 & 13.10 \\
$\mathrm{Si}$ & 1.11 & 1.31 & 1.52 & 1.79 \\
$\mathrm{Cr}$ & 2.62 & 2.81 & 1.94 & 2.07 \\
$\mathrm{Mn}$ & 1.31 & 1.34 & 3.01 & 0.07 \\
$\mathrm{Fe}$ & 61.53 & 59.98 & 42.35 & 41.23 \\
$\mathrm{Co}$ & 10.07 & 10.21 & 6.57 & 6.65 \\
$\mathrm{Ni}$ & 6.14 & 6.54 & 4.02 & 4.27 \\
Mo & 3.72 & 3.93 & 1.49 & 3.93 \\
Total amount & 100.00 & 100.00 & 100.00 & 100.00 \\
\hline
\end{tabular}

\section{Conclusion}

(1) After the shot peening, the surface of the sample showed obvious plastic deformation, the surface roughness increased, and the arithmetic mean roughness $R_{a}$ increased from $0.47 \mu \mathrm{m}$ before shot peening to $1.33 \mu \mathrm{m}$.

(2) Shot peening significantly increased the hardness of the sample, and the hardness of the outermost layer increased from $476 \mathrm{HV}$ before shot peening to $497 \mathrm{HV}$, and the depth of the hardened layer formed by shot peening was about $150 \mu \mathrm{m}$.

(3) The residual compressive stress on the surface of the sample after shot peening is increased from -375 MPa to $-475 \mathrm{MPa}$, and the maximum residual compressive stress value is about -518 $\mathrm{MPa}$. It is located at a depth of $50 \mu \mathrm{m}$ from the surface, and the residual compressive stress layer formed by shot peening is about $134 \mu \mathrm{m}$ deep.

(4) The mass fractions of $\mathrm{C}, \mathrm{Si}, \mathrm{Cr}$ and other elements in the sample after shot peening are slightly increased, which is mainly caused by the phenomenon of material transfer during shot peening.

\section{References}

[1] YABO H, CHAO F D, HONG L, et al. Study on the hydrogen embrittlement of Aermet100 using hydrogen permeation and SSRT techniques[J]. Metallurgical and Materials Transactions, 2017, 48(6):4046-4055.

[2] XIAO Z Y, YE X, LU Y H, et al. Effect of shot peening on bending fatigue strength and fractograph of Fe-2Cu-2Ni-1Mo-1C [J]. Journal of Mechanical Engineering, 2013, 49(20):152-157.

[3] SUN H X, ZHU Y L, HOU S, et al. Effects of fatigue load on residual stress and microstructure of 17CrNiMo6 shot peening strengthened layer [J]. China Surface Engineering, 2016, 29(4):44-48.

[4] XU X C, LIU D X, GUAN Y Y, et al. Effect of shot peening on the surface integrity and fatigue property of 2060 
aluminum lithium alloy [J]. Mechanical Science and Technology for Aerospace Engineering, 2016, 35(9):1445-1449. [5] Guo Changgang, Xu Yimeng, Wang Lingqian, et al. Effect of shot peening on corrosion behavior of magnesium alloy in simulated body fluid[J]. Surface Technology, 2017, 46(8):188-193.

[6] (SAE) AMS-S-13165-1997, Shot peening of metal parts[S].

[7] ZHOU S, XIE L Y, HUI L, et al. Influence of shot peening on fatigue life of 2XXX aluminum alloy [J]. Journal of Materials Engineering, 2014, (12):86-91.

[8] GAO Y K, WU X R. Experimental investigation and fatigue life prediction for 7475-T7351 aluminum alloy with and without shot peening induced residual stresses [J]. Acta Materialia, 2011, 59:3737-3747.

[9] DALAEI K, KARISSON B, SVENSSON L E. Stability of residual stresses created by shot peening of pearlitic steel and their influence on fatigue behaviour [J]. Procedia Engineering, 2010, 2(1):613-622.

[10] LIU W C, DONG J, ZHANG P, et al. Improvement of fatigue properties by shot peening for Mg-10Gd-3Y alloys under different conditions [J]. Materials Science and Engineering, 2011, 528(18):5935-5944.

[11]KAZUYUKI O. Fatigue life enhancement of aluminum alloy for aircraft by fine particle shot peening (FPSP)[J]. Journal of Materials Processing Technology, 2011, 211(8):1395-1399.

[12] ZHENG Linbin. The effect of shot peening residual stress and roughness on fatigue life of 2024 aluminum alloy by simulation and experimental study [D]. Shandong: Shandong University, 2017: 45-57.

[13] Wang Xin, Jiang Zhihua, Zeng Houxiang, et al. Effect of shot-peening on low-cycle fatigue property of 18\%Ni ultra-high strength steel [J]. Journal of Beijing University of Aeronautics and Astronautics, 2014, 40(5):608-612.

[14] Nouguier L C, Zarwel M, Diviani C, et al. Surface impact analysis in shot peening process [J]. Wear, 2013, 302(1-2):453-462.

[15] Chen G Q, Jiao Y, Tian T Y, et al. Effect of wet shot peening on Ti-6Al-4V alloy treated by ceramic beads[J]. Transactions of Nonferrous Metals Society of China, 2014, 24(3):690-696.

[16] Ma Jinfang, Hu Lanqing, Xu Bingshe. Substance transfer phenomenon in the process of high-energy shot peening [J]. Rare Metal Meterials and Engineering, 2007, 36(4):744-746.

[17] Hu Gengxiang, Qian Miaogen. Metallography [M]. Shanghai: Shanghai Science and Technology Press, 1980:32. 